\title{
Revisitando propostas e iniciatiuas de organização do ensino em ciclos: um debate atual e necessário
}

\section{Revisiting proposals and initiatives for the organization of teaching in cycles: a current and necessary debate}

\section{Revisando propuestas e iniciativas de organización de la enseñanza en ciclos: un debate actual y necesario}

\author{
Ocimar Munhoz Alavarse ${ }^{1}$ \\ Universidade de São Paulo (USP), Professor; Coordenador do Grupo de Estudos e Pesquisas \\ em Aualiação Educacional (Gepaue) \\ Paulo Henrique Arcas ${ }^{2}$ \\ Universidade de São Paulo, Pós-doutorando e Consultor em Educação

\section{Cristiane Machado ${ }^{3}$} \\ Universidade Estadual de Campinas (Unicamp), Professora da Faculdade de Educação
}

Resumo: Neste artigo recuperam-se e analisam-se propostas e iniciativas de organização do ensino fundamental em ciclos das redes municipais de Belo Horizonte, Porto Alegre e São Paulo implantadas na primeira metade dos anos 1990 e que serviram de referência para outras redes de ensino, principalmente após a promulgação da Lei de Diretrizes e Bases da Educação Nacional (LDB). No contexto de políticas de educação que têm preconizado sua qualidade como expressas nos resultados de avaliações externas em larga escala, considerase necessário recuperar iniciativas que, sem necessariamente recusar a utilização desses resultados, buscaram alterar a organização curricular do ensino fundamental com vistas à ampliação da qualidade na perspectiva de sua democratização.

Palavras-chave: Democratização do ensino. Organização curricular. Ciclos. Ensino fundamental.

Doutor e Mestre em Educação e Pós-Doutorando pela Faculdade de Educação da Universidade de São Paulo (USP).

2 Doutor e Mestre em Educação pela Faculdade de Educação da Universidade de São Paulo (USP). Doutora em Educação pela Faculdade de Educação da Universidade de São Paulo; Mestre em Educação pela Faculdade de Educação da Universidade Estadual de Campinas (Unicamp). 
Abstract: This article retrieves and analyzes proposals and initiatives for the organization of elementary education in cycles of the municipal networks of Belo Horizonte, Porto Alegre and São Paulo implemented in the first half of the 1990s and which served as a reference for other education networks, especially after the promulgation of LDB. In the context of education policies that have advocated their quality as expressed in the results of large-scale external evaluations, it is considered necessary to recover initiatives that, without necessarily rejecting the use of these results, sought to change the curricular organization of elementary education with a view to expanding quality in the perspective of its democratization.

Keyworks: Democratization of education. Curriculum organization. Cycles. Elementary school.

Resumen: Este artículo recupera y analiza propuestas e iniciativas de organización de la enseñanza fundamental en ciclos de las redes municipales de Belo Horizonte, Porto Alegre y São Paulo implantadas en la primera mitad de los años 1990 y que sirvieron de referencia para otras redes de enseñanza, principalmente luego de la publicación de la Ley Nacional de Educación. En el contexto de políticas de educación que han preconizado su calidad como expresadas en los resultados de evaluaciones externas a gran escala, se considera necesario recuperar iniciativas que, sin necesariamente rechazar la utilización de esos resultados, buscaron alterar la organización curricular de la enseñanza fundamental con el propósito de mejorar la calidad y democratizar el acceso a la educación básica.

Palabras clave: Democratización de la enseñanza. Organización curricular. Ciclos. Educación básica.

\section{INTRODUÇÃO}

objetivo principal neste estudo foi recuperar e problematizar iniciativas das redes municipais de ensino de Belo Horizonte, Porto Alegre e São Paulo na implementação da organização curricular do ensino fundamental em ciclos. Ainda que remontando a um processo desencadeado no início e meados dos anos 1990 e que perdeu proeminência no debate das políticas 
públicas educacionais, por motivos variados e que entre eles se destacam as avaliações externas em larga escala e a educação integral/em tempo integral, mas que, tudo indica, contém aspectos que mantêm sua atualidade e, sobretudo, potencial para impulsionar a busca de uma educação de qualidade para todos os alunos, como salientado em Alavarse (2009a, 2009b).

Ainda que não tenha se consagrado exatamente um modelo de organização curricular em ciclos, mas, sim, um processo histórico tensionado pelas maneiras de se garantir a educação de massas, no interior do qual se encontram concepções diferenciadas tanto em relação aos fins dessa própria escolarização quanto sobre sua realização material e organizacional, na qual se possa aplicar o conceito de recontextualização a que recorre Mainardes (2005), como trajetória entre as formulações mais explicitamente teóricas até sua incorporação pelos agentes últimos da atividade pedagógica.

Destacam-se as concepções e características formuladas nessas iniciativas, mesmo que tenham sido parciais ou limitadas, especialmente nos momentos iniciais da implantação, que podem ser apreciadas e reelaboradas, com a devida crítica, para, eventualmente, constituírem-se em aportes para a consecução de trabalhos, propostas e estudos no âmbito de políticas públicas.

Dispomos em Sousa et al. (2003) e Barretto e Sousa (2004a, 2004b, 2005) de amplo levantamento da produção acadêmica sobre ciclos e progressão, além dos trabalhos de Barretto e Mitrulis (2001) e Mainardes (2001, 2006), que subsidiam e ao mesmo tempo indicam a necessidade de continuidade de investigação sobre o tema. Desse acervo, depreende-se que a imensa maioria dos trabalhos se concentra sobre os fundamentos dos ciclos, e, por conta disso, a realidade de sua implementação ainda demanda um aprofundamento, uma vez que existem fortes indícios de que não se obteve, até o momento, uma formulação que superasse a organização seriada. Tal constatação, evidentemente, pode revelar, após uma análise mais acurada, que talvez algumas iniciativas não pretendessem efetivamente produzir alterações essenciais, mas, como hipótese, pode-se também constatar que não se desenvolveu adequadamente uma apreciação tanto da seriação - e seu lastro profundo nas práticas e representações - quanto da formulação efetiva de uma proposta diferenciada de organização do ensino fundamental, obrigatório e, 
portanto, de massas. Muito provavelmente, tal situação decorra da constatação de Barretto e Sousa (2004a, p. 65), visto que:

A denominação ciclos, para alternativas de organização escolar não seriada, é muito recente. Registra-se o seu surgimento apenas em meados dos anos 80 e, desde então, os ciclos passaram a ser acompanhados de diferentes qualificativos.

No caso brasileiro, os ciclos tendem a ser uma medida intermediária entre o regime seriado e aquele de promoção automática, como o da Inglaterra de há décadas atrás, em que se inspiraram as primeiras propostas brasileiras.

Esse caráter de inovação, associado ao hibridismo ciclo e séries - como se verifica nos registros do Inep quanto às formas de organização

- ressaltam a importância de aprofundar a formulação de ciclos, visto que, novamente com base nesse referido estudo, chega-se por vezes a questões e ponderações que devem ser equacionadas na teoria e na prática, como é o caso das prescrições curriculares, pois, para as autoras,

[...] embora todas as experiências de ciclos se proponham a superar a fragmentação provocada pelo regime seriado - umas com pretensões bastante ousadas de mudança na lógica da escola, outras quase que tão somente removendo os limites das séries para fins de promoção ou retenção do aluno -, em nenhuma das experiências deixa de existir a referência às séries nas práticas docentes. Isso leva a supor que um projeto educacional de larga duração, como o do ensino fundamental de 8 ou de 9 anos, talvez não possa prescindir de certos princípios de ordenação dos conteúdos escolares. Ora, se não é desejável que eles funcionem da mesma maneira que nas séries, como repensá-los a partir da lógica dos ciclos? (BARRETO; SOUSA, 2004a, p. 71).

Então, os dimensionamentos e demarcação dessas três experiências, que ao nosso ver foram as que mais fortemente se configuraram como iniciativas que buscaram romper com a lógica da escola seriada, têm como objetivo central decantar, na medida do possível, uma resposta para o desafio da democratização do ensino de que são portadoras as propostas de ciclos. 


\section{AS INICIATIUAS DAS REDES MUNICIPAIS DE SÃO PAULO, BELO HORIZONTE E PORTO ALEGRE}

Para a configuração da concepção e das condições de implantação de ciclos encontramos empiricamente iniciativas desenvolvidas, ainda que, total ou em curso com "desfigurações", associadas a contribuições teóricas, estabelecem um patamar de formulações que favorecem a problematização geral do ciclos e, principalmente, podem constituir um acervo de referências para futuras iniciativas quer no âmbito das políticas educacionais, quer para o acúmulo de conhecimento sobre a temática das formas de organização escolar.

Para essas redes, destaca-se que os documentos que estabeleceram, inicialmente, os fundamentos fundantes da proposição de reorganização do ensino fundamental continuam sendo de referência para a compreensão do quadro atual. No caso de Belo Horizonte e Porto Alegre, as gestões posteriores fizeram apenas reedições de Belo Horizonte (1994) e Porto Alegre (1996). Quanto à rede paulistana, além de não mais existir a estrutura implantada em 1992, que é objeto de exposição a seguir, as administrações que se seguiram à que tomou a decisão em tela não se ocuparam sequer de retomá-la.

agrupamento dessas experiências, constituído pelas iniciativas das redes municipais de Belo Horizonte, Porto Alegre e São Paulo, apesar de suas especificidades que são apresentadas a seguir, justifica-se por alguns traços comuns extraídos de forma marcante em suas formulações e delineamentos, tem-se assim: indução da estruturação curricular sob eixos temáticos, e não exclusivamente disciplinares, questionando-se a própria noção de conhecimento escolar; redimensionamento dos tempos e espaços escolares; valorização das experiências e conhecimentos dos alunos; consideração das diferenças entre os educandos na interação com o trabalho escolar; ênfase no trabalho coletivo, tanto docente quanto discente; avaliação formativa, sem fins classificatórios; organização dos agrupamentos de alunos, com base em objetivos de aprendizagem e grupos etários.

Tais propostas de ciclos colocam um desafio: o de pensar a escola em bases muito distintas daquelas sobre as quais tradicionalmente se organiza. 
A democratização do ensino é vista não apenas em termos quantitativos expressos em números de acesso, permanência e conclusão -, e a função da escola é tomada em sua essência, qual seja, garantir que alunos e professores experimentem um processo de conhecimento emancipatório, o que ocorreu, obviamente, não isento de contradições e tensões. De todo modo, a concepção de ciclos emergente implicaria um processo de escolarização que deve se revestir de uma nova natureza, com fins radicalmente novos: a formação ampliada de seres humanos.

A implantação dos ciclos na Rede Municipal de Ensino de São Paulo, pioneira quanto ao fato de envolver o conjunto do ensino fundamental e relevante pelas dimensões próprias dessa rede e pelo conteúdo da proposta, iniciou-se em 1992 e foi seguida pelas Redes Municipais de Belo Horizonte, a partir de 1994, e Porto Alegre, a partir de 1995. Em todas elas, definiu-se a organização do ensino fundamental em três ciclos, integrando as antigas séries iniciais e finais. Essas últimas administrações implantaram os ciclos no ensino fundamental com nove anos de duração e, ainda que focando a questão curricular, vão desenvolver uma fundamentação para a segmentação dos ciclos mais centrada nas faixas etárias, entendidas como determinantes de características decisivas para o agrupamento dos alunos. Embora não se possa fazer uma generalização entre as iniciativas de ciclos e as orientações político-partidárias para a educação, notadamente porque nesse tocante não há uma identidade a ser assinalada por conta das disparidades observadas sobretudo nos dias correntes, as três iniciativas deram-se sob os auspícios de administrações dirigidas pelo Partido dos Trabalhadores (PT). O Quadro 1 ilustra o cenário das gestões no momento de implantação da proposta de ciclos em cada um dos municípios, destacados em negrito, e as gestões subsequentes. 
Quadro 1 - Propostas de Ciclos e Gestões Municipais

\begin{tabular}{|c|c|c|c|}
\hline Gestão & Belo Horizonte & Porto Alegre & São Paulo \\
\hline \multirow{2}{*}{$\begin{array}{l}1989 \\
1992\end{array}$} & $\begin{array}{l}\text { Pimenta da Veiga } \\
\text { (PSDB) 1989/90 }\end{array}$ & \multirow{2}{*}{ Olívio Dutra (PT) } & \multirow{2}{*}{ Luiza Erundina (PT) } \\
\hline & $\begin{array}{l}\text { Eduardo Azeredo } \\
\text { (PSDB) 1990/92 }\end{array}$ & & \\
\hline $\begin{array}{l}1993 \\
1996\end{array}$ & Patrus Ananias (PT) & Tarso Genro (PT) & Paulo Maluf (PPB) \\
\hline $\begin{array}{l}1997 \\
2000\end{array}$ & Célio de Castro (PSB) & Raul Pont (PT) & Celso Pitta (PPB) \\
\hline \multirow{2}{*}{$\begin{array}{l}2001 \\
2004\end{array}$} & $\begin{array}{l}\text { Célio de Castro (PSB) } \\
2001\end{array}$ & $\begin{array}{l}\text { Tarso Genro (PT) } \\
2001 / 02\end{array}$ & \multirow{2}{*}{ Marta Suplicy (PT) } \\
\hline & $\begin{array}{l}\text { Fernando Pimentel (PT) } \\
\text { 2001/04 }\end{array}$ & $\begin{array}{l}\text { João Verle (PT) } \\
\text { 2002/04 }\end{array}$ & \\
\hline \multirow{2}{*}{$\begin{array}{l}2005 \\
2008\end{array}$} & \multirow[b]{2}{*}{ Fernando Pimentel (PT) } & \multirow[b]{2}{*}{ José Fogaça (PPS) } & $\begin{array}{l}\text { José Serra (PSDB) } \\
2005 / 06 \\
\end{array}$ \\
\hline & & & $\begin{array}{l}\text { Gilberto Kassab (PFL/ } \\
\text { DEM) } \\
2006 / 08 \\
\end{array}$ \\
\hline \multirow{2}{*}{$\begin{array}{l}2009 \\
2012\end{array}$} & \multirow{2}{*}{ Mario Lacerda (PSB) } & $\begin{array}{l}\text { José Fogaça (PMDB) } \\
2009 / 10\end{array}$ & \multirow{2}{*}{ Gilberto Kassab (DEM) } \\
\hline & & $\begin{array}{l}\text { José Fortunati (PDT) } \\
2010 / 12\end{array}$ & \\
\hline $\begin{array}{l}2013 \\
2016 \\
\end{array}$ & Mario Lacerda (PSB) & José Fortunati (PDT) & Fernando Haddad (PT) \\
\hline $\begin{array}{l}2017 \\
2020\end{array}$ & Alexandre Kalil (PHS) & $\begin{array}{l}\text { Nelson Marchezan } \\
\text { Júnior } \\
\text { (PSDB) }\end{array}$ & $\begin{array}{l}\text { João Dória Júnior } \\
\text { (PSDB) }\end{array}$ \\
\hline
\end{tabular}

Fonte: elaborado pelos autores com informações recolhidas nos sítios das prefeituras de Belo Horizonte, Porto Alegre e São Paulo.

\section{CICLOS NA REDE MUNICIPAL DE ENSINO DE SÃO PAULO}

Influenciado, fortemente, por iniciativas francesas (FRANCE, 1991), o processo de implementação na Rede Municipal de Ensino de São Paulo, em todas as escolas de ensino fundamental, em 1992, desencadeado pela administração do Partido dos Trabalhadores, cujo mandato estendeu-se de 1989 a 1992, destacou-se pela magnitude dos desafios enfrentados ao se administrar 
uma rede de ensino de tal porte, ${ }^{4}$ transformando-a em um caso paradigmático, mediante uma política educacional que se formulava pelo objetivo, segundo seus dirigentes, de construção de uma escola pública popular, democrática e de qualidade.

Desse arcabouço político, derivaram quatro diretrizes: 1) democratização da gestão, com o objetivo de incrementar - ou estabelecer - a participação dos vários segmentos nas decisões da política educacional; 2) democratização do acesso, pois, no início da gestão, verificava-se um contingente significativo de crianças fora da escola; 3) educação de jovens e adultos, já que, naquela época, São Paulo contava com um número estimado de um milhão de analfabetos e 2,5 milhões de pessoas com menos de quatro anos de escolaridade; 4) nova qualidade de ensino, segundo a qual se procurou desenvolver mediante três grandes eixos: a) movimento de reorientação curricular; b) interdisciplinaridade; e c) formação permanente dos educadores.

Importante registrar que as ações decorrentes da quarta diretriz resultaram em mais de 1.500 projetos nas escolas, desencadeados com base no incentivo à análise da realidade local, sobre a qual alunos e professores deveriam se debruçar para o levantamento de temas para alimentar o processo educacional e pedagógico. Da busca dessa nova qualidade, por meio de discussões, em um primeiro momento em nível local e, posteriormente, em fóruns regionais e centrais, chegou-se, em 1991, à elaboração de um novo Regimento Comum das Escolas Municipais, no qual se formulou a proposta de ciclos dessa administração.

Cortella (1992, p. 6, grifo nosso), que foi chefe de gabinete de Paulo Freire e depois, de 1991 a 1992, secretário de educação, sintetizou a experiência nos seguintes termos:

De 1989 a 1991 estivemos criando condições estruturais mais amplas para uma alteração profunda no ensino fundamental no que se refere à sua organização curricular; embora já tivéssemos convicções prévias

4 Em 1992, a Rede Municipal contava com 353 escolas de ensino fundamental regular com mais de 440 mil alunos e quase 30 mil professores. 
quanto à necessidade de romper com a seriação estanque no $1^{\circ}$ grau, não queríamos implantar uma mudança que fosse feita sem uma recuperação das escolas, um trabalho forte com as comunidades, a valorização profissional dos educadores e sua formação permanente.

O novo Regimento, apoiado na concepção de uma escola flexível, democrática e autônoma, propôs uma organização escolar regida pelos princípios da continuidade, flexibilidade e articulação, sobretudo na transição das séries iniciais, garantindo-se um regime de ciclos para todo o Ensino Fundamental.

A proposta de organização em ciclos visa à construção de uma escola que rompe com as práticas de seletividade, exclusão social e autoritarismo; a ruptura com o regime de seriação (um dos fatores básicos para o elevado índice de reprovação, evasão e fracasso escolar em nosso país) não buscava diminuir artificialmente nossos índices de retenção e evasão pois, se não por outras razões, tínhamos já conseguido reduzi-los, entre 1989 e 1991, aos mais baixos patamares das últimas décadas (em 1991, média de $12 \%$ de retenção e $5 \%$ de evasão).

Dessa forma, a partir de 1992, o Ensino Fundamental foi estruturado em três ciclos: ciclo inicial (antigas $1^{a}$, $2^{a}$ e $3^{a}$ séries), ciclo intermediário (antigas $4^{a}, 5^{a}$ e $6^{a}$ séries) e ciclo final (antigas $7^{a}$ e $8^{a}$ séries); a avaliação passou a ser contínua e qualitativa, com relatórios semestrais que devem ser discutidos com os educandos e seus responsáveis (quando for o caso), as notas foram substituídas por três conceitos (plenamente satisfatório, satisfatório, insatisfatório); e, finalmente, a retenção só ocorre ao final de cada ciclo (se retido, o educando refaz somente o último ano do ciclo correspondente).

Uma das iniciativas mais marcantes, não somente do ponto de vista do envolvimento de recursos, como também de sua contribuição na concepção de ciclos, foi o Movimento de Reorientação Curricular. Tal movimento, procurando pensar o conjunto de ações da escola, desencadeou uma proposta de trabalho interdisciplinar articulado com os objetivos explicitados da radical democratização da escola (CHIAPPINI; MIRANDA; EVARISTO: 1994, p. 25). Assim, nesse Movimento, encontra-se o veio substancial que permitiu aflorar a proposta de ciclos, sendo imprescindível destacar que se colocava como central uma proposta de organização escolar ou, melhor ainda, como condição para se pensar esta ou aquela forma de organização, a discussão daquilo que a escola se propõe a fazer, o que define como objetivos e finalidades. A discussão curricular ganha, portanto, centralidade que remete os professores a uma 
tarefa a qual, se não altera completamente sua tradição, subverte uma prática arraigada nos ambientes escolares.

Na Exposição de motivos do novo Regimento (SÃO PAULO, 1992, p. 7, grifo nosso), encontramos o tópico referente aos ciclos, no qual várias dimensões são apresentadas. Destacando-as, temos:

Visando à construção de uma escola que rompa com sua prática de seletividade, exclusão social e autoritarismo para com seus alunos, de qualquer idade, é que estamos propondo a organização do ensino fundamental na forma de ciclos.

No conjunto de fatores que contribuem para o elevado índice de reprovação e evasão escolar de crianças, adolescentes, jovens e adultos, poderíamos apontar o regime de seriação (as séries ou termos) como sendo uma das contribuições para o fracasso escolar do aluno no ensino fundamental.

[...] vem sendo comprovado que a seriação atua de maneira decisiva, perversa e seletiva no desenvolvimento da vida escolar dos alunos de qualquer faixa etária.

Diferentemente do que se costuma constatar na análise de documentos legais e oficiais, a preocupação com a continuidade do processo escolar, associada à segmentação entre "primário" e "ginásio", aparece explicitamente como processo de rompimento dos mecanismos de reprovação e repetência, que produzem uma escolarização, para a maioria das crianças em escolas seriadas, sob a ameaça de terem sua escolarização marcada pela descontinuidade de turma e de processo de construção de conhecimento com seu grupo. Assim, é enfatizada a necessidade de articulação de todo o ensino fundamental. Como outra consequência, houve a alteração facultativa na jornada dos professores, criando uma Jornada Especial Integral (JEI), na terminologia atual, pela qual o optante, recebendo por 40 aulas semanais, despenderia 25 em atividades com alunos, oito em horário coletivo, três em horário individual na escola e quatro em horário individual de livre exercício.

Essa concepção de ciclos, embora não desse conta de todos os desafios que a temática encerra, revelava uma preocupação, ao fixar uma base temporal que extrapola a tradição de associar o ano letivo ao ano civil, de 
dotar a escola, seus professores e alunos de uma flexibilidade que permita mais amadurecimento recíproco. Mas isso somente pode ocorrer se houver um planejamento - daí a discussão do currículo - que incorpore essa nova base temporal. $\bigcirc$ contrário, como verificado em algumas experiências, redunda em ciclos como um aglomerado de séries, fruto mais da aritmética do que de princípios político-pedagógicos.

Portanto, essa concepção de ciclos articulava um conjunto de aspectos inseparáveis. Articulava uma visão de democratização da escola como garantia de acesso e permanência, concebendo que a escola apenas se justifica quando explicita a relação de seus objetivos e atividades, consubstanciados em seu currículo. Tratava, por conseguinte, de democratizar a escola com a proposta de que fosse significativa para seus alunos, tomandoos como sujeitos, e, principalmente, lidando com os conhecimentos de modo a compreendê-los historicamente. Sublinhava, também, que a necessidade de se superar a organização seriada, arraigada na tradição de fragmentação e empobrecimento do conhecimento e do trabalho docente, produzindo blocos estanques em que se transformaram as séries iniciais e as finais do ensino fundamental, e, sobretudo pela concepção avaliativa que a ela se associava, de condicionar fortemente o trabalho pedagógico para fins seletivos.

Como decorrência dessa concepção, foi concebida a ação supervisora na perspectiva de partilhar com as escolas os desafios de uma política educacional, em contraste com uma tradição verticalista que tende a desresponsabilizar quem formula e implanta as medidas, impondo às escolas, praticamente, todo o ônus dos encaminhamentos e desdobramentos de uma política, como se esta se resumisse a uma simples receita.

Portanto, essa iniciativa de implementação de ciclos - que vigorou até 1997, pois, desde 1998 (SÃO PAULO, 1998), a rede possui dois ciclos de quatro anos cada, à semelhança da rede estadual,$-{ }^{5}$ por sua concepção, entra para a

\footnotetext{
5 A rede estadual paulista em 1997, por meio da Deliberação n. 9/97 e Indicação n. 8/97, ambas do Conselho Estadual de Educação (CEE), organizou o ensino fundamental em dois ciclos: Ciclo I ( $1^{a}$ a $4^{a}$ série) e Ciclo II ( $5^{a}$ a $8^{a}$ série), e adotou a progressão continuada no interior de cada ciclo, sendo permitida a reprovação dos estudantes por desempenho somente no final de cada ciclo, ou seja, $4^{a}$ e $8^{a}$ série. Em 201 l, uma nova organização foi feita (Resolução SE n. 81, de 16 de
} 
história. Não porque tenha exaurido suas potencialidades, mas pela amplitude das formulações e proposições, colocando-se como algo a ser recuperado e incorporado ao debate pedagógico atual sobre ciclos. Em Gomes (2004, p. 117), tal perspectiva se reforça pela constatação de que:

Parece-nos, diante do modo como os Ciclos estão sendo desenvolvidos nas escolas municipais paulistanas, que muito pouco foi apropriado da proposta original elaborada pela gestão do Partido dos Trabalhadores em 1992 e que parte das atitudes dos educadores escolares está muito longe de uma concepção progressista de educação que conceba o aluno como sujeito do processo de ensino e aprendizagem. Podemos notar, também, que ainda não se instalou em nossas escolas públicas uma prática que rompa com o autoritarismo e com a conformação/ aceitação passiva dos princípios da sociedade liberal [...]

Desde a gestão 1989-1992, para além da alteração de três para dois ciclos feita sem a menor justificativa política ou pedagógica em 1998 (SÃO PAULO, 1998), a proposta de ciclos não foi merecedora de preocupação das gestões subsequentes, com igual empenho, com pequena exceção para o mandato do prefeito Fernando Haddad (2013-2016). Silva (2004, p. 36), ao fazer um balanço de três anos da administração de Marta Suplicy (2003-2006), comenta que os ciclos, que foram uma marca do PT na cidade, até aquele momento, não haviam sido mencionados. E quando consultamos algumas publicações do período com chamada sobre a temática, encontramos que cada unidade escolar deveria repensar os ciclos (SÃO PAULO, 2003a, 2003b), ou, então, são lançados questionamentos genéricos sobre a proposta (SÃO PAULO, 2004a, 2004b). Esse panorama leva Gomes (2004, p. 103) a ponderar, em pesquisa, ao final do ano 2003, como podia aquela administração deixar de discutir tal tema.

dezembro de 2011 ) modificando a forma de progressão dos estudantes nos ciclos, mas mantendo a divisão em dois ciclos do ensino fundamental. 


\section{CICLOS NA REDE MUNICIPAL DE ENSINO DE BELO HORIZONTE}

A adoção de ciclos em Belo Horizonte, configurando o que se denominou Escola Plural, teve, em Miguel Arroyo, Secretário Adjunto de Educação, um expoente destacado, que assim sustentava a proposta de Ciclos de Desenvolvimento ou de Formação, que se contrastaria com os chamados Ciclos de Aprendizagem, como se deu em São Paulo. Para Arroyo (1999, p. 158, grifo nosso),

\begin{abstract}
É uma procura, nada fácil, de organizar o trabalho, os tempos e espaços, os saberes, as experiências de socialização da maneira mais respeitosa para com as temporalidades do desenvolvimento humano. Desenvolver os educandos na especificidade de seus tempos-ciclos, da infância, da adolescência, da juventude ou da vida adulta. Pensamos em Ciclos de Formação ou de Desenvolvimento Humano.

As idades da vida, da formação humana passam a ser o eixo estruturante do pensar, planejar, intervir e fazer educativos, da organização das atividades, dos conhecimentos, dos valores, dos tempos e espaços. Trabalhar em um determinado tempo-ciclo da formação humana passa a ser o eixo identitário dos profissionais da educação básica e de seu trabalho coletivo e individual.
\end{abstract}

A elaboração da proposta político-pedagógica da Escola Plural iniciou-se com um amplo processo de problematização nas escolas, que, inclusive, foram estimuladas, desde o início da gestão em 1993, ao desenvolvimento de projetos próprios. Desse momento, resultou o documento que apontava, então, para a organização do ensino fundamental em ciclos, em cuja apresentação (BELO HORIZONTE, 1994, p. 1) delineiam-se seus contornos de democratização conjugados com a alteração da organização da escola, pois: "A preocupação com o direito de permanência de crianças, jovens e adultos em uma escola de qualidade orientou a sua elaboração. Reduzir 'os índices de evasão e reprovação exige mudanças profundas na estrutura da escola pública de ensino fundamental'." 
Destaca-se que o tempo de escola deveria se caracterizar, primeiramente, por uma socialização-vivência de alunos e profissionais e, em segundo lugar, para garantir a onilateralidade da formação humana, em oposição à tradição de unilateralidade, até mesmo para valorizar a vivência do presente, não apenas em razão do futuro. Especificamente quanto aos ciclos se afirmava, no texto, que

A escola vem retomando a centralidade de sua função socializadora de valores, crenças, rituais; vêm se assumindo como espaço de construção de identidades, de autoimagens e de hábitos de convívio na diversidade. Nestes avanços, a pedagogia redescobre a força socializadora e formadora do convívio entre alunos e alunas da mesma idade ou ciclo de idades de formação.

As iniciativas diversas, que tentam manter cada educando com seus pares de idade de socialização, buscam ser fiéis a essa velha e renovada pedagogia que tinha sido marginalizada e sacrificada em nome da fidelidade estreita à lógica de avaliações de rendimentos médios, de reprovações, repetências e interrupções e rupturas de turmas e de quebras de percursos de socialização próprios de cada idade - ciclo de formação. (BELO HORIZONTE, 1994, p. 13, grifo nosso).

Essa proposta, portanto, nega que os conteúdos sejam os elementos a definirem os tempos escolares, reconhecendo a enorme dificuldade em sua alteração, fruto de mais de um século no qual esse tempo obedeceu a preceitos de calendário, níveis, séries, semestres, bimestres, avaliação, reprovação e repetência. Salienta-se, ainda, que essa forma tradicional tinha uma lógica, pautada nos conteúdos, transmissiva, cumulativa, homogeneizadora dos desempenhos e fragmentadora do processo de conhecimento. Propunha que os conteúdos escolares se submetessem aos critérios dos ciclos de formação, de tal forma que o ensino e a aprendizagem de habilidades e saberes básicos deveriam estar a serviço da formação de identidades mais equilibradas, como fruto da vivência em grupos de mesma idade.

Sustentando que há no interior do ciclo da educação básica ciclos menores, mais homogêneos, definia-se que: 
eixo vertebrador da organização do tempo de Educação Básica será o educando e seus ciclos ou idades mais homogêneas de formação. A partir desse eixo, compreendemos como mais adequado do ponto de vista do desenvolvimento formativo dos alunos, a organização do atual período de Educação Básica ( $1^{\circ} \mathrm{grau}$ ) em 3 (três) CICLOS DE FORMAÇÃO:

PRIMEIRO CICLO BÁSICO (período característico da infância) compreenderá os alunos(as) que estiverem na faixa de idade 6-7; 7-8; 8-9.

SEGUNDO CICLO BÁSICO (período característico de préadolescência) compreenderá os alunos(as) que estiverem na faixa de idade 9-10; 10-11; 11-12.

TERCEIRO CICLO BÁSICO (período característico da adolescência) compreenderá os alunos(as) que estiverem na faixa de idade 12-13; 13-14; 14-15. (BELO HORIZONTE, 1994, p. 19).

Concebia-se a possibilidade, em caráter excepcional ao final de um ciclo, de um aluno continuar por mais um ano nesse ciclo, caso se avaliasse que ele não tivesse adquirido um desenvolvimento equilibrado em todas as dimensões de sua formação.

Outra questão relevante diz respeito aos conteúdos, que deveriam ser definidos com base em que se considerava básico em cada disciplina, em uma perspectiva adequada a cada idade, procurando dar-lhes significado, com a inclusão de conteúdos que impulsionassem as diversas potencialidades dos educandos. Esse processo deveria se materializar mediante a definição do coletivo de professores de cada ciclo, desfocando o eixo das disciplinas para questões que pudessem propiciar o desenvolvimento dos alunos, sobretudo pelas problematizações, inclusive como recurso para delimitar interesses e domínios dos alunos diante de várias possibilidades temáticas, das quais se deveriam efetuar recortes para a definição de eixos de todo o programa, ponderando-se que,

Se temos como objetivo o desenvolvimento integral dos alunos em uma realidade plural, é necessário que passemos a considerar as questões e problemas enfrentados pelos homens e mulheres de nosso tempo como objeto de conhecimento.

$\bigcirc$ aprendizado e vivência das diversidades de raça, gênero, classe, a relação com o meio ambiente, a vivência 
equilibrada da afetividade e sexualidade, o respeito à diversidade cultural, entre outros, são temas cruciais que, hoje, todos nós nos deparamos e, como tal, não podem ser desconsiderados pela escola.

$[\ldots]$

Pensando em um desenho curricular, o que se busca é o rompimento com um modelo compartimentado em disciplinas isoladas, onde o conhecimento se apresenta descontextualizado da realidade. A proposta é que este currículo seja construído a partir da definição coletiva dos temas que representam os problemas colocados pela atualidade, não de forma paralela às disciplinas curriculares e sim transversais a elas.

$[\ldots]$

Nesta perspectiva, o conhecimento escolar é construído a partir do reconhecimento das questões que são de interesse social e da sua reflexão, tendo como referência - conhecimento cultural acumulado, presente nas disciplinas. (BELO HORIZONTE, 1994, p. 32).

Dois outros aspectos salientes estavam na avaliação e no trabalho coletivos das escolas. A avaliação, além de ser destituída de seu caráter tradicional classificatório, colocava-se como um instrumento, nas formas inicial, contínua e final, a serviço da aprendizagem, devendo, ainda, pautar-se não apenas na apreciação dos alunos, mas de todo o processo educativo. Quanto ao trabalho coletivo, começou-se por definir novos esquemas de trabalho que permitissem jornadas com dedicação para além das típicas horas em sala de aula, em atividades diferenciadas com outros professores ou alunos.

Dalben (2000, p. 53, grifo nosso), estudando essa proposta e particularmente as dificuldades para sua implementação, afirmou sobre seus impactos mais gerais que:

As inovações propostas requerem modificações relacionadas não apenas a novos conhecimentos a serem adquiridos pelo conjunto dos professores que a fazem, mas, e prioritariamente, a modificações de cunho ético e político exigindo a assimilação de novos valores educativos.

Nesse sentido, o trabalho pedagógico ganha mais relevância, pois a definição dos grupos de idade não esgota toda a caracterização dos 
educandos, e, para tanto, o envolvimento do professor é condição para que se possa desenvolver um processo educativo efetivamente centrado nos sujeitos de desenvolvimento, nos quais se devem converter todos os alunos. A delimitação das atividades a serem desencadeadas é incompatível aos valores educativos que pressupõem o trabalho docente como algo solitário e atomizado, embora seja pertinente se ter presente que, via de regra, a formação do professor é baseada nesses marcos individualizantes.

Como uma última menção a essa proposta, Barretto (1998, p. 31) indica que na Escola Plural:

A lógica da construção da identidade social tem precedência social [...] sobre a lógica institucionalizada do ensino, visto que esta última costuma estar historicamente associada a etapas e pré-requisitos que tradicionalmente têm-se prestado a justificar a repetência. Os processos de socialização que passam, via de regra, despercebidos no cotidiano da instituição escolar recebem particular atenção.

\section{CICLOS NA REDE MUNICIPAL DE ENSINO DE PORTO ALEGRE}

A proposta político-pedagógica da Rede Municipal de Ensino de Porto Alegre denominou-se Escola Cidadã (PORTO ALEGRE, 1996) e também procurou enfatizar o combate à evasão e à repetência como forma de garantir o acesso ao conhecimento. Essa proposta, principia-se por centralizar a importância do currículo que se "expressa através de um conjunto de atividades que de maneira direta ou indireta interfere no processo de criação, produção, transmissão e assimilação do conhecimento" (PORTO ALEGRE, 1996, p. 9), apoiando-se em uma visão processual, que permitisse o movimento de açãoreflexão-ação, e estruturou-se em três ciclos, de três anos cada. Afirma-se que essa organização promove um continuum no processo de ensino-aprendizagem, um planejamento e a própria prática pedagógica, respeitando, além do mais, o ritmo, o tempo e as experiências dos educandos. Para tanto, 
Em cada Ciclo de Formação existe um conjunto de princípios e conhecimentos que norteia, complexifica e aprofunda 0 trabalho pedagógico e o caminho percorrido desde o primeiro ano do primeiro ciclo até o último ano do terceiro ciclo, isto é, do início até o final da educação básica. Contudo, cada ciclo, acompanhando as características dos educandos em suas diferentes idades e situação sócio-cultural, não pode se tornar cristalizado, pois à medida que os educandos chegam aos princípios e objetivos propostos para cada ciclo, suas vivências no ciclo deverão ser enriquecidas com outras informações e conhecimentos, dando a necessária continuidade no processo de aprendizagem. Desse modo, na escola, organiza-se um movimento pedagógico flexível voltado para o sucesso dos educandos e não para o seu fracasso. Assim, a estrutura por Ciclos operacionaliza, de forma mais ampla, um enfrentamento sério do fracasso escolar, contendo uma perspectiva educacional onde há respeito, entendimento e investigação sobre os processos sóciocognitivos de produção do conhecimento, pelos quais passa cada educando. Eis porque se torna fundamental a ação consciente dos educadores, tendo este olhar de continuidade e garantindo que as dificuldades dos educandos sejam superadas no decorrer de cada Ciclo. (PORTO ALEGRE, 1996, p. 11).

Segue-se uma justificativa para cada ciclo de formação, ancorando-se, muito mais do que na proposta de Belo Horizonte, em pressupostos psicológicos para definir as faixas etárias, citando-se Piaget e Vygotsky principalmente. Assim, o primeiro ciclo (dos 6 aos 8 anos e 11 meses) teria como traço agrupar os alunos que se encontram em um período "em que aparecem mudanças significativas na interação social do educando, especialmente daqueles que nunca frequentaram uma escola, por isso o trabalho no ciclo deve propiciar uma articulação estreita com a educação infantil." (PORTO ALEGRE, 1996, p. 20-21 ). Já o segundo ciclo (dos 9 anos aos 11 anos e 11 meses), com alunos em uma etapa intermediária, já começaria a incorporar a conquista da autonomia pessoal e social, não apenas na relação com o conhecimento, como também com a escola. E, por fim, o terceiro ciclo (dos 12 anos aos 14 anos e 11 meses) seria composto por alunos que estariam passando para a maneira adulta de pensar, já com a capacidade para pensar em termos abstratos desenvolvida.

Para tanto, a organização do ensino foi feita por complexos temáticos - assuntos ou relações profundas - que concentram conceitos e temas a serem 
extraídos de um processo de problematização e que norteiam, em seu estudo e aprofundamento, toda a atividade do ano ou do ciclo. Tais complexos temáticos demandaram uma sistematização das diferentes áreas do conhecimento, à luz dos objetivos mais gerais de cada ciclo.

Mais uma vez, encontramos a preocupação para o lugar que deve ocupar a avaliação como um processo que não pode se centrar no aluno, mas, sim, voltar-se para a escola como um todo, ressaltando-se seu caráter processual, contínuo, participativo, diagnóstico e investigativo, para permitir um redimensionamento da ação educativa, quando necessário.

Krug (2002), ao estudar as iniciativas de Porto Alegre, ressalta a proposta de complexos temáticos reportando-se às suas fontes de inspiração que estariam em Pistrak (2000), autor russo que produziu na década de 1920, e em Paulo Freire, por conta dos temas geradores. Para tanto é necessária a pesquisa socioantropológica para que tais complexos possam se configurar, sendo que para Pistrak (2000, p. 136-137)

critério necessário para a seleção dos temas dever ser procurado no plano social e não na pedagogia "pura". $\bigcirc$ complexo deve ser importante, antes de tudo, do ponto de vista social, devendo servir para compreender a realidade atual.

[...]

$\bigcirc$ estudo dos complexos representa uma série de elos em uma única corrente, conduzindo à compreensão da realidade social.

Krug (2002) defende que é também nessa reorganização do currículo, articulada com os grupos e idades, que se poderia superar o questionamento sobre as dificuldades que os ciclos impõem ao processo pedagógico ao não comporem as turmas por proximidade de domínio cognitivo. Evidentemente, no caso dos complexos temáticos, os conteúdos não são definidos completamente de fora para dentro; ao contrário, procuram envolver os alunos em sua definição e delimitação, o que, por si, já induz a uma outra relação com o conhecimento. Indica, também, que a Escola Cidadã não prevê a retenção, mas, sim, uma forma de progressão, na qual é delineado o modo pelo qual as escolas vão 
acompanhar os alunos os quais considera estarem apresentando dificuldades particulares que, por isso, exigiriam uma intervenção sistemática.

Com vistas a esse tipo de organização, baseado em boa medida nas faixas etárias, encontramos no trabalho de Galvão (1993, p. 36), quando de seus comentários sobre o Plano (Projeto) Langevin-Wallon, uma justificativa apoiada nas teorias de Henri Wallon:

\begin{abstract}
A inspiração psicológica do Projeto traduz-se pela proposta de adequação do ensino às etapas do desenvolvimento da criança. As solicitações e exigências escolares, tal como a própria estrutura do ensino, deveriam apoiarse sobre o conhecimento científico do ser humano em desenvolvimento, sobre a psicogênese. Segundo Wallon, a educação dever atender às necessidades imediatas de cada etapa de desenvolvimento infantil, assegurando a plena realização das disposições e aptidões atuais, ao mesmo tempo em que prepara a etapa seguinte, nutrindo na criança o desenvolvimento das atitudes e funções que estão por vir e que, de alguma forma, já se manifestam em sua atividade presente.

Os ciclos de ensino teriam estrutura diferenciada para atender às necessidades das faixas etárias. Suas estruturas distinguir-se-iam quanto ao tipo de conteúdo, ao tempo de trabalho dirigido, à proporção entre disciplinas do ensino comum e do especializado, ao grau de responsabilidade na gestão da escola, conforme as possibilidades e necessidades da criança. Por exemplo, pelo aumento progressivo da carga horária destinada às especialidades, respeitam-se o lento processo de especialização das aptidões individuais, pela predominância, no currículo, de atividades expressivas (subjetivas) ou de observação (objetivas), e o ritmo pulsante do desenvolvimento, marcado pela alternância entre fases predominantemente centrípetas (quando predominariam atividades expressivas) e centrífugas (quando predominariam atividades de observação e de aquisição de conhecimento).
\end{abstract}

\title{
6 CONSIDERAÇÕES FINAIS
}

$\mathrm{Na}$ escola de massas com sucesso para todos, para superar o que Dubet (2008) chamou de ilusão da igualdade de oportunidade e avançar no sentido daquilo que Crahay (2012) apontou como igualdade de resultados, 
provavelmente, a organização do ensino fundamental em ciclos seja uma alternativa a ser retomada plenamente. Retomar plenamente significa colocar a perspectiva de organizar o ensino em ciclos como foco das políticas educacionais, pois, apesar da manutenção dessa forma de organização, em muitos casos, o que tem ocorrido na prática é apenas a eliminação da possibilidade de reprovar, sem mudanças profundas na estrutura da escola, na discussão do currículo e na formação dos professores que levariam e promoveriam efetivamente a transformação necessária para a adoção do ensino organizado em ciclos.

Isso não necessariamente indica que se deve abandonar as avaliações externas em larga escala, inclusive por suas potencialidades formativas para docentes, como demonstrado em Alavarse, Machado e Arcas (2017), muito menos a ideia de educação em tempo integral. Até porque alavancar resultados escolares e qualificar o tempo escolar se encontram no seio de propostas de organização do ensino em ciclos.

\section{REFERÊNCIAS}

ALAVARSE, O. M. A organização do ensino fundamental em ciclos: algumas questões. Revista Brasileira de Educação, Rio de Janeiro, v. 14, n. 40, p. 3550, jan./abr. 2009a.

ALAVARSE, O. M; MACHADO, C.; ARCAS, P. H. Avaliação externa e qualidade da educação: formação docente em questão. Revista Diálogo Educacional, Curitiba, v. 17, n. 54, p. 1353-1375, jul./set. 2017.

ALAVARSE, O. M. Organização do ensino fundamental em ciclos e avaliação. São Paulo em Perspectiva, São Paulo, v. 23, n. 1, p. 73-89, jan./jun. 2009b.

ARROYO, M. G. Ciclos de desenvolvimento humano e formação de educadores. Educação \& Sociedade, Campinas, ano 20, n. 68, p. 143-162, dez. 1999.

BARRETTO, E. S. S.; MITRULIS, E. Trajetória e desafios dos ciclos escolares no país. Estudos Avançados, São Paulo, v. 15, n. 42, p. 103-140, maio/ago. 2001. 
BARRETTO, E. S. S.; SOUSA, S. M. Z. L. Ciclos: estudos sobre as políticas implementadas no Brasil. In: REUNIÃO ANUAL DA ANPED - GT ESTADO E POLIÍTICA EDUCACIONAL, 27., 2004, Caxambú. Anais... Caxambú, 2004a.

BARRETTO, E. S. S.; SOUSA, S. M. Z. L. Estudos sobre ciclos e progressão escolar no Brasil: uma revisão. Educação e Pesquisa, São Paulo, v. 30, n. l, p. 31-50, jan./abr. 2004b.

BARRETTO, E. S. S.; SOUSA, S. M. Z. L. Reflexões sobre as políticas de ciclos no Brasil. Cadernos de Pesquisa, São Paulo, v. 35, n. 126, p. 659-688, set./ dez. 2005.

BARRETTO, E. S. S. Tendências recentes do currículo do ensino fundamental no Brasil. In: BARRETTO, E. S. S. (Org.). Os currículos do ensino fundamental para as escolas brasileiras. Campinas: Autores Associados; São Paulo: Fundação Carlos Chagas, 1998. p. 5-42.

BELO HORIZONTE. Secretaria Municipal de Educação. Escola Plural: proposta político-pedagógica. Belo Horizonte: SMED, out. 1994. Cadernos Escola Plural, 0.

CHIAPPINI, L.; MIRANDA, J. L.; EVARISTO, M. C. Interdisciplinaridade na escola pública: a experiência paulista na gestão de Paulo Freire e a participação da universidade. In: FAUNDEZ, A. (Org.). Educação, desenvolvimento e cultura: contradições teóricas e práticas. São Paulo: Cortez, 1994. p. 13-45.

CORTELLA, M. S. A reconstrução da escola (a Educação Municipal em São Paulo de 1989 a 1991). Em Aberto, Brasília, ano 1 1, n. 53, p. 54-63, jan./mar. 1992.

CRAHAY, M. (Dir.). L'école peut-elle être juste et efficace?: de l'égalité des chances à l'égailté des acquis. 2. ed. rev. et actualisée. Bruxelles: De Boeck, 2012. Pédagogies en Développement.

DALBEN, A. I. L. de F. A prática pedagógica e os ciclos de formação na Escola Plural. In: DALBEN, A. I. L. de F. (Org.). Singular ou plural? Eis a escola em questão. Belo Horizonte: Ed. UFMG/FAE/GAME, 2000. p. 53-66.

DUBET, F. O que é uma escola justa? A escola das oportunidades. Tradução Ione Ribeiro Valle. São Paulo: Cortez, 2008.

FRANCE. Ministère de l'Éducation Nationale de la Jeunesse et des Sports. Direction des Écoles. Les cycles à l'école primaire. Paris: Centre National de Documentation Pédagogique / Hachette Écoles, 1991. Une école pour l'enfant, des outils pour les maîtres. 
GALVÃO, I. Uma reflexão sobre o pensamento pedagógico de Henri Wallon. In: BORJA, A. de (Org.). Construtivismo em revista. São Paulo: FDE. Diretoria Técnica, 1993. p. 33-39.

GOMES, C. A. Quinze anos de ciclos no ensino fundamental: uma análise dos percursos. Revista Brasileira de Educação, n. 25, p. 39-52, jan./abr. 2004.

KRUG, A. Ciclos de formação: uma proposta transformadora. 2. ed. Porto Alegre: Mediação, 2002.

MAINARDES, J. A organização da escolaridade em ciclos: ainda um desafio para os sistemas de ensino. In: FRANCO, C. (Org.). Avaliação, ciclos e promoção na educação. Porto Alegre: Artmed, 2001. p. 35-54.

MAINARDES, J. Organização da escolaridade em ciclos no Brasil: revisão da literatura e perspectivas para a pesquisa. Educação e Pesquisa, São Paulo, v. 32, n. l, p. 1l-30, jan./abr. 2006.

MAINARDES, J. Origem e desenvolvimento da escola em ciclos no Brasil. In: JORNADA DO HISTDBR, 6., 2005, Ponta Grossa. Anais... Ponta Grossa: Universidade Estadual de Ponta Grossa, 2005.

PISTRAK, M. M. Fundamentos da Escola do Trabalho. Tradução Daniel Aarão Reis Filho. São Paulo: Expressão Popular, 2000.

PORTO ALEGRE. Prefeitura Municipal de Porto Alegre. Secretaria Municipal de Educação. Ciclos de formação: proposta político-pedagógica da Escola Cidadã. Porto Alegre: SMED, dez. 1996. Cadernos Pedagógicos, n. 9.

SÃO PAULO (Município). Caderno temático de formação I: leitura de mundo, letramento e alfabetização: diversidade cultural, etnia, gênero e sexualidade. 2003a.

SÃO PAULO (Município). Caderno temático de formação: ensino fundamental. 2004a.

SÃO PAULO (Município). EducAç̧ão, n. 4: cidade educadora-educação inclusiva: um sonho possível. 2003b.

SÃO PAULO (Município). EducAç̧ão, n. 5: gestão, currículo e diversidade. 2004b.

SÃO PAUlO (Município). Portaria n. 1.971, de 02 de junho de 1998. Diário Oficial do Município, São Paulo, 03 jun. 1998. 


\section{SÃO PAULO (Município). Regimento Comum das Escolas Municipais de} São Paulo. São Paulo, 1992.

SILVA, C. C. et al. Educação na capital paulista: um ensaio avaliativo da política municipal (2001-2002). São Paulo: Instituto Pólis, PUC-SP, 2004.

SOUSA, S. M. Z. L. et al. Ciclos e progressão escolar: indicações bibliográficas. Ensaio: avaliação de políticas públicas em Educação, Rio de Janeiro, v. 11, n. 38, p. 99-114, jan./mar. 2003.

Recebido em 30 de janeiro de 2018 Aceito em 07 de abril de 2018

Endereços para correspondência: Rua Vergueiro, 3166, apto 121, Vila Mariana, 04102-001, São Paulo, São Paulo, Brasil; arcasmg@uol.com.br 